\title{
ANÁLISIS CONTRASTIVO DE LA (DES)CORTESÍA EN LOS COMENTARIOS DIGITALES DEL PERIÓDICO 20MINUTOS.ES Y DEL FACEBOOK DE VIAJACONTUMASCOTA.COM: ANONIMATO Y COMUNIDAD VIRTUAL
}

\section{CONTRASTIVE ANALYSIS OF THE (IM)POLITENESS IN THE DIGITAL COMMENTS OF THE 2OMINUTOS.ES NEWSPAPER AND VIAJACONTUMASCOTA.COM'S FACEBOOK: ANONYMITY AND VIRTUAL COMMUNITY}

\author{
Julia Sanmartín SÁez \\ (Universitat de València. Grupo Valesco) \\ julia.sanmartin@uv.es
}

Enviado: 16/03/2019

Aceptado: 11/06/2019

\begin{abstract}
Resumen
Esta investigación analiza las diferencias entre dos tipos de discursos digitales: las intervenciones reactivas a cinco posts por parte de los seguidores de una página de Facebook, ViajaconTuMascota.com, en la que existe cierta camaradería por la afición compartida; y los comentarios de lectores anónimos, entre los que no se establece esa solidaridad, a cinco noticias del periódico digital, 20minutos.es. Se pretende comprobar cómo inciden estas diferencias, la presencia o ausencia de solidaridad y el anonimato frente a la identidad real, cuando se producen desacuerdos: si se mantiene la cortesía social, a través de una cortesía mitigadora, o si se quiebra al activarse una estrategia de ciberdescortesía.
\end{abstract}

PALABRAS CLAVE: descortesía, cortesía, atenuación y géneros digitales.

\begin{abstract}
This research analyzes the differences between the two types of digital discourses: reactive interventions to the five posts by the followers of a Facebook page, ViajaconTuMascota.com, in which there is a certain camaraderie by the shared hobby; and the comments of anonymous readers, among which that solidarity is not established, to five news of the digital newspaper, 20minutos.es. The aim is to verify how these differences affect, the presence or absence of solidarity and anonymity affect real identity, when disagreements occur: if social politeness is maintained, through a mitigating politeness, or if it breaks when it is activated a cyber-badness strategy.

KEYWORDS: impoliteness, politeness, mitigation and digital genre.
\end{abstract}

1 Proyecto MINECO, La atenuación pragmática en su variación genérica. Géneros discursivos escritos y orales en el español de España y de América, del Ministerio de Economía y Competitividad, FFI2016-75249-P.

Para citar este artículo / To cite this article: Sanmartín Sáez, Julia (2019). Análisis contrastivo de la (des)cortesía en los comentarios digitales del periódico 20minutos es y del Facebook de ViajaconTuMascota.com: anonimato y comunidad virtual. ELUA, 33: 173-194. doi: 10.14198/ELUA2019.33.9

Enlace / Link: http://dx.doi.org/10.14198/ELUA2019.33.9 


\section{INTRODUCCIÓN. LA DESCORTESÍA EN LOS MEDIOS DE COMUNICACIÓN}

Parece, a juzgar por los actuales estudios, que en aquellos escenarios con audiencia (Fuentes y Alcaide 2008: 16) la hostilidad lingüística se encuentra en el punto de mira: «Los hablantes actúan afanosamente en pos del conflicto, de tal forma que se busca deliberadamente el desequilibrio entre las imágenes sociales de los distintos interlocutores.»

Así, en los medios de comunicación tradicionales, como la televisión o la radio (Culpeper et al. 2003; Fuentes coord. 2013), resulta habitual constatar interacciones descorteses, tanto en tertulias o debates políticos y de crónica social (Blas Arroyo 2001; Brenes 2009; González Sanz 2010; Brenes y González Sanz 2013) como en reality shows (Blas Arroyo 2014).

También en los medios de comunicación digitales se registra este uso descortés, beligerante y agresivo por parte de los cibernautas en las diversas plataformas y redes sociales (Lea et al. 1992; Tabachnik 2012; Parker 2017): en intervenciones o comentarios en Facebook (Chierichietti 2014; Vivas 2015), en listas de correo electrónico (Fuentes 2009a), en You Tube (Bou y Garcés 2014), en blogs del español peninsular (Castro 2017), en blogs periodísticos de Chile (López y González 2013), en Twitter y Facebook en el contexto político-ideológico de Argentina (Kaul y Cordisco 2014) o en la prensa digital (Mancera 2009; Ruiz et al. 2010; Fuentes 2013; Arancibia y Montecino 2013; Pardo y Noblía 2015; Noblía 2015; Moya 2015; Sal Paz 2016).

Y, por supuesto, no faltan los análisis comparativos sobre usos descorteses en las diversas plataformas y teniendo en cuenta aspectos concretos, como el tipo de perfil privado o público o la conexión grupal (Vivas y Ridao 2015).

En suma, agresión verbal y descortesía provocan que los índices de audiencia se eleven, y el enfrentamiento verbal se convierte en protagonista indiscutible. Se califica incluso como descortesía mediática (Blas Arroyo 2014). La bibliografía sobre el tema empieza a ser tan extensa que ya se han sintetizado todos estos estudios en artículos como el de Mancera (2015) o se han realizado tesis doctorales sobre los actos de habla hostiles en los medios de comunicación virtual, en este caso con especial atención a Twitter (Díaz Pérez 2012).

No obstante, también surgen algunos estudios, aunque en menor medida, sobre la cortesía valorizadora en Facebook (Vivas 2014) o sobre la atenuación en los comentarios de los periódicos digitales (Moya y Carrió 2018).

\section{LAS INTERACCIONES REACTIVAS EN DOS CIBERGÉNEROS: LOS CO- MENTARIOS}

Como punto de partida de esta investigación, se considera que cada género discursivo, sea digital o no, presentará una serie de variables que van a incidir en la mayor o menor cortesía lingüística y, sobre todo, en la descortesía entre los emisores-receptores cuando surgen desencuentros en las interacciones discursivas. De hecho, en la actualidad se prioriza este marco epistemológico variacionista (Blas Arroyo 2014; Brenes y González Sanz 2013).

Para este estudio, se analizan los comentarios digitales en dos tipos de cibergéneros: las respuestas de los seguidores de un grupo de Facebook, ViajaconTuMascota a cinco posts; y las intervenciones reactivas de los lectores a cinco noticias del periódico digital, 20minutos. es. La comunidad virtual de ViajaconTuMascota.com se caracteriza por la existencia de cierta solidaridad entre sus miembros por la afición compartida, la tenencia de mascotas, y 
estos muestran la identidad real; por el contrario, en los comentarios de los periódicos digitales prevalece la identidad anónima y no existe una camaradería. De este modo, se pretende comprobar cómo dos variables, la solidaridad de grupo o su ausencia, y el anonimato de los internautas o su identidad real, repercuten en la formulación de la (des)cortesía empleada en estas intervenciones. En ambos casos se han seleccionado posts y noticias iniciales que versaran sobre perros para posibilitar la comparación sobre un tema similar en cuanto a su posible grado de controversia.

Se describirá, en primer lugar, cada uno de los tipos de discursos analizados (la interacción en el Facebook de ViajaconTuMascota.com y en el periódico digital 20.Minutos. es) porque otras páginas de Facebook o periódicos digitales no comparten exactamente los mismos rasgos: el tipo de periódico y su ideología, la temática de las noticias (Fuentes 2013) o la configuración de comunidad de usuarios de un Facebook (Chierichietti 2014) modifican los parámetros condicionantes del texto.

\subsection{La interacción en una página de Facebook: ViajaconTuMascota.com}

El primer género analizado es una interacción en la red social Facebook, vinculada a ViajaconTuMascota.com, una página web de una empresa privada que promociona alojamientos que aceptan animales. La red social Facebook constituye un género nativo digital o cibergénero original, caracterizado, en pocas palabras, por un soporte gráfico multimodal (se combinan imagen, texto y sonido), la actualización de contenidos, la posibilidad de interacción de distintos sujetos y la gestión por parte de un usuario, el administrador de la página, de toda la información.

Si bien Facebook surge como un espacio socializador en el que el usuario publicita sus vivencias personales a sus amigos (con su perfil real, fotos, etc.) y recibe constante información de otros usuarios, pronto las empresas utilizan esta herramienta como una forma de promocionar sus productos (Chierichietti 2014) y, por ello, existe un tenor transaccional más o menos solapado y encubierto por parte del administrador, los posibles receptores se convierten en seguidores (González y Sanmartín 2013) y se activan una serie de estrategias de interacción. En el caso de las empresas se suele combinar la página promocional comercial clásica con la interacción dinámica de Facebook, entre otros. No obstante, en el caso de la participación de los seguidores, el tenor se puede etiquetar como meramente socializador: el seguidor solo desea mostrar su opinión, su reflexión personal, sobre el post inicial o sobre las intervenciones de otros usuarios.

En este tipo de textos los rasgos lingüísticos observados suelen ser similares a los textos enmarcados en la oralidad y en lo coloquial (Sanmartín 2007; Mancera y Pano 2013): se escribe, pero el grado de elaboración no es elevado; se busca escribir como se habla (Briz 2012; Briz 2014) y se emplean estrategias discursivas para aproximar a los interlocutores, como los emojis o emoticonos, la imitación de las risas con las grafías (jaja), etc.

El Facebook analizado de la página ViajaconTuMascota.com surge con una finalidad transaccional: promocionar establecimientos que admiten mascotas. En la actualidad cuenta con 300.00 seguidores (septiembre de 2018). En general estos seguidores son personas que mantienen una afición común (tener mascota, normalmente perros) y se identifican por este rasgo como integrantes de esta especie de comunidad virtual o digital, generada por su participación en los comentarios (Yus 2001; Tabachnik 2012). De hecho, en la ventana derecha 
de la página se considera como comunidad. Además, suelen presentarse con un nombre y perfil auténtico (aunque con excepciones ${ }^{1}$ ) frente al posible anonimato habitual del género digital (Tabachnik 2012), ya que esta red social se caracteriza por el deseo de mostrar, visibilizar y publicitar al resto de usuarios la vida privada del que escribe. Los seguidores de esta comunidad emplean una jerga para referirse a este ámbito (peludo 'perro', perrhijo 'perro tratado como hijo', vete 'veterinario', prote 'protectora', BC 'Border Collie', PPP 'perro potencialmente peligroso', etc.) y comparten una serie de valores (por ejemplo, consideran que los canes son un valor positivo): forman parte de un grupo de referencia. Se constituyen, pues, como comunidades de acuerdo. Además, parece que los integrantes pertenecen a un estrato generacional medio de edad y poseen cierto poder adquisitivo.

Para promocionar los establecimientos, el gestor de la página no solo informa de los alojamientos turísticos que admiten mascotas, sino que propone diversos posts iniciales para dinamizar la interacción discursiva entre los usuarios y conseguir que, de un modo habitual, sus seguidores reciban información y a su vez participen en la interacción discursiva (Vivas y Ridao 2015) con una finalidad meramente socializadora. En esa interacción asincrónica y socializadora de los seguidores, las intervenciones pueden darse respecto al post inicial o en relación a la intervención de otro seguidor. Esto último da lugar a las consideradas como escisiones en la interacción que se representan visualmente como respuestas que es necesario desplegar. De este modo, se diferencian dos tipos de receptores: el interpelado en la intervención y la audiencia (el resto de seguidores) que lee el texto.

A pesar de que la temática suscitada pueda plantear algún tipo de controversia o polémica, los usuarios suelen mantener cierta cortesía social y atenúan las discrepancias posibles. De hecho, en internet existe una propuesta de normas de cortesía o netiquette (Yus 2001) y, en concreto, en Facebook se incluye un enlace para acceder a las Normas de interacción. Condiciones y políticas de Facebook, en el que se especifican tres niveles de ataque y se añade la importancia de la identidad real en la responsabilidad del comentario. Consideramos como parámetro esencial para el mantenimiento de la cortesía comunicativa el mostrar esta identidad real.

Los seguidores de la página comercial de Facebook ViajaconTuMascota.com mantienen un sentimiento de afiliación (Bravo 2005) al ser amantes de sus mascotas. Nótese en (1) la separación entre nosotros (propietarios de mascotas, miembros de la comunidad, y el propio gestor de la página y redactor del post) y vosotros (ayuntamientos) en el post (artículo o entrada) inicial. Este nosotros inclusivo aparece en muchos comentarios, tal y como se muestra en (2) en luchemos.

\section{(1)}

[Post inicial]

Queridos Ayuntamientos... Cuando habilitéis una PLAYA para nuestros PERROS, recordad que los dueños de los mismos los amamos, los cuidamos, son como nuestros hijos, son nuestra FAMILIA. ¿Vosotros iríais a una playa de PIEDRAS como esta? ¿NO Verdad? ¿Y por qué nosotros si? [206 comentarios. En general todos muestran acuerdo respecto a la propuesta del post]

[ViajaconTuMascota]

1 En la muestra del Facebook analizado destacan algunos nombres como Bendita Lokura, Negrita Neo o Anuska Pituska. 
(2)

Elena: Los perros son perros. (...)Y que cada uno haga lo que quiera, pero lo de comprarle un modelito a juego...luchemos porque nos dejen ir con ellos a más lugares, que se endurezcan las penas contra el abandono y maltrato animal [Viajacon TuMascota]

Al realizar la búsqueda del corpus de comentarios de Facebook, se ha constatado que el desacuerdo es mucho menos frecuente que el acuerdo; además, se indica de un modo explícito «estoy de acuerdo contigo», como uno de los comentarios de intervenciones reactivas habituales (así en 3), y como elementos reactivos de otros usuarios a un comentario aparecen sobre todo los emoticonos o emojis: "me gusta" (pulgar levantado) y "me encanta" (corazón) y a veces "me entristece" (carita llorando), los cuales no se han reproducido en los ejemplos.

El empleo continuo de emojis variados en las propias intervenciones de los seguidores contribuye a incrementar la unión entre los usuarios de grupo, tal y como se aprecia en (3), con las imágenes de perros, personas, caritas contentas o corazones.

(3)

[Post inicial] 8 cosas que no le puedes ocultar a tu perro

No hay absolutamente nada que le puedas ocultar. $;$ iSabe todo sobre ti! 8

-Pepe: [Cesar Gonzalez] jajajaj me encanta lo de: sabe donde has estado... eso es cuando rompe el sofá jajajajajaja y lo de las intencioness

$[\ldots]$

-Juan: Sí a todo. Estrictamente cierto :-)

$[\ldots]$

- Teres:[ Luisa Garcia] mira alma no es superdotada (-), :-)

[57 comentarios de acuerdo] [ViajaconTuMascota ]

\subsection{La interacción en periódicos digitales: los comentarios de los lectores}

El segundo género tomado como objeto de estudio son los comentarios de los lectores a una noticia del periódico digital 20minutos.es. En la actualidad, los periódicos digitales se pueden considerar como un género ya existente, es decir, constituye un mero traslado del texto a la red, si bien es cierto que se permiten algunas variantes, ya que es posible el comentario asincrónico en la misma noticia de los lectores y la interacción entre ellos. De hecho, en esa interacción, como en el caso anterior, se pueden producir intervenciones reactivas entre los lectores, las cuales van apareciendo sangradas a la derecha para mostrar estas escisiones dialógicas.

Los periódicos digitales ya cuentan incluso con normas para gestionar esta interacción de los lectores, por lo que, como en el caso anterior, las normas constituyen una prueba de que se produce el conflicto discursivo entre los lectores y la necesidad de regularlos. En este caso, la identidad discursiva de los lectores establece un mayor anonimato (Mancera 2009) que en el caso del Facebook anterior y, además, no forman parte de una comunidad virtual tan concreta y específica como la de ViajaconTuMascota.com: solo comparten el hecho de leer y comentar noticias de un periódico, por lo general tras registrarse en este. Para Fuentes (2013: 214), los lectores comentaristas se suelen agrupar en una especie de comunidades discursivas a partir de los rasgos ideológicos sustentados por las propias líneas editoriales de los diferentes periódicos. Sin embargo, en el caso del periódico analizado, 20.minutos. 
es, generalista y divulgativo, no parece que exista una comunidad virtual de valores que conecte a los participantes como integrantes de un grupo de referencia, más allá del hecho de participar con su opinión en un espacio público.

Como se ha indicado, se mantiene el anonimato del lector ya que solo se exige un «nombre de usuario» de 23 caracteres, que no sea malsonante ni difamatorio. Desde el punto de vista de las variables sociolingüísticas, aquellos que redactan comentarios quizá pertenezcan a un estrato generacional y sociocultural similar al de los participantes de ViajaconTuMascota.com: son sujetos mayores de 30 años y, al menos, nivel medio, como lectores de textos periodísticos.

Se aprecia una clara diferencia en la identidad (real o ficticia) mostrada por los usuarios en ambos géneros discursivos: en esta página de Facebook se suele utilizar una identidad real (con nombres y apellidos, foto personal o de la mascota, etc.) y, por el contrario, en el periódico digital analizado el lector comentarista se presenta por lo general con un apodo singular y una imagen ingeniosa. Este es un rasgo que condicionará notablemente la participación discursiva. Permite que los sujetos actúen con un elevado grado de descortesía, hostigamiento y agresividad verbal amparados ${ }^{2}$ por la protección de su anonimato (Fuentes y Alcaide 2008; Crystal 2002, Mancera 2009, Fuentes 2009b, Díaz Pérez 2012): diga lo que diga, nadie me puede identificar.

Como ya se ha indicado, el anonimato se sirve de un apodo ingenioso que protege la identidad real: trolleitor, El Verrugas, gotasca, Madrox, Almamia, etc. De hecho, cuando el lector comentarista adopta un apodo que podría identificarse con su nombre real, el tono de su discurso es menos agresivo. Por ello, en los propios comentarios se alude a la figura de troll o trol de algunos comentaristas, personas que emiten mensajes provocadores, ofensivos y agresivos, y al borrado de los comentarios por parte de los administradores, como sucede en (4) por el contenido tan hiriente o inapropiado:

(4)

-HaRDaWaY: Supongo que eres troll. Todos los dias vivo la situacion de varios perros gruñendo y lanzandose como locos a intentar morder a mi perro debajo de mi casa, asi que no me vengas a contar tonterias. [20minutos.es]

-jcarpi: Me lo habéis borrado dos veces. [20minutos.es]

A pesar del registro formal empleado en la redacción de la noticia de prensa, con elevado grado de planificación, objetividad y tenor informativo, los comentarios de los lectores no son atenuados ni corteses, sino más bien todo lo contrario cuando surgen las diferencias de opinión. Como ya señala Fuentes (2013), los comentarios se caracterizan por el empleo de un registro coloquial (con errores ortográficos) y una fuerte subjetividad. Además, como en el caso de las intervenciones del Facebook, surge un doble receptor si el lector responde al comentario anterior de otro lector, ya que el resto de lectores formará parte de la audiencia que recibe el mensaje. Ahora bien, en el Facebook las intervenciones de los seguidores dotan de verdadero contenido al entramado discursivo: son las respuestas las que tejen el discurso y lo dotan de entidad; en cambio, en la prensa digital lo esencial es la noticia. Los comenta-

2 También Díaz Pérez (2012) enumera siete elementos que favorecen esta expresión agresiva en las redes sociales: anonimato, distanciamiento, distancia espacial, rapidez en la transmisión, escaso esfuerzo de codificación, desinhibición y alcance del mensaje. 
rios de los lectores solo favorecen la imagen positiva del periódico como motor de opinión (Fuentes 2013: 208) y elemento para fidelizar a los lectores, si bien en ocasiones atentan contra la imagen del propio diario (Noblía 2015: 18) y este puede censurar las opiniones.

\subsection{Síntesis de rasgos}

A continuación se presentan en la tabla (5) los factores situacionales y discursivos, caracterizadores de los dos cibergéneros. Se han destacado en gris sus diferencias.

\begin{tabular}{|c|c|c|}
\hline Rasgos & $\begin{array}{l}\text { Facebook } \\
\text { ViajaconTuMascota.com }\end{array}$ & $\begin{array}{l}\text { Periódico digital } \\
\text { 20minutos.es }\end{array}$ \\
\hline Relación funcional de igualdad & \multicolumn{2}{|c|}{$\begin{array}{l}\text { Participantes: seguidores o lectores (con administrador o } \\
\text { gestor de los comentario en relación asimétrica ) }\end{array}$} \\
\hline [*Perfil del usuario] & \multicolumn{2}{|l|}{$>30$ años y nivel medio } \\
\hline Receptor & \multicolumn{2}{|c|}{$\begin{array}{l}\text { Audiencia (conjunto de receptores) } \\
\text { y/ o posible destinatario seleccionado o apelado }\end{array}$} \\
\hline Reversibilidad de papeles & \multicolumn{2}{|c|}{$\begin{array}{l}\text { El seguidor / comentarista puede leer (recibir) y emitir } \\
\text { mensajes a su vez }\end{array}$} \\
\hline Finalidad & \multicolumn{2}{|c|}{ Socializadora (opinar desde la subjetividad del yo) } \\
\hline Temática & \multicolumn{2}{|l|}{ Cotidiana (sobre mascotas) } \\
\hline Asincrónica & \multicolumn{2}{|l|}{+} \\
\hline Planificación & \multicolumn{2}{|c|}{ Escrita (pero cercano o imitación de lo oral) } \\
\hline Registro de la intervención & \multicolumn{2}{|l|}{ Coloquial (y con errores ortográficos) } \\
\hline Soporte de interacción (marco) & \multicolumn{2}{|l|}{ digital } \\
\hline Género encadenado & \multicolumn{2}{|c|}{$\begin{array}{l}\text { El comentario siempre es una intervención reactiva a } \\
\text { un texto anterior (post o noticia), si bien en el caso del } \\
\text { Facebook analizado el comentario resulta fundamental. }\end{array}$} \\
\hline $\begin{array}{l}\text { Emisor } \\
\text { (real o anónimo) }\end{array}$ & $\begin{array}{l}\text { Identidad más real con nombres } \\
\text { y apellidos (foto y perfil) }\end{array}$ & $\begin{array}{l}\text { Identidad ficticia con } \\
\text { apodo (sin foto ni datos } \\
\text { reales) }\end{array}$ \\
\hline $\begin{array}{l}\text { Comunidad virtual de valores } \\
\text { compartidos } \\
\text { Relación vivencial }\end{array}$ & $\begin{array}{l}(+) \text { (pero sin gran unión) } \\
(+)\end{array}$ & $\begin{array}{l}(-) \\
(-)\end{array}$ \\
\hline $\begin{array}{l}\text { Interactividad } \\
\text { (alternancia de intervenciones de } \\
\text { usuarios) }\end{array}$ & $\begin{array}{l}\text { Comentarios a un post y a otros } \\
\text { comentarios } \\
(++)\end{array}$ & $\begin{array}{llr}\text { Comentarios } & \text { a } & \text { una } \\
\text { noticia y a otros } \\
\text { comentarios }\end{array}$ \\
\hline $\begin{array}{l}\text { Escisión dialógica (intervenciones } \\
\text { al margen del diálogo principal) }\end{array}$ & $(++)$ & $(+)$ \\
\hline Modalidad & Multimodal $(+)$, emojis y risas & Texto \\
\hline Registro del post o noticia & Neutro-informal & Neutro-formal \\
\hline
\end{tabular}

(5) Tabla contrastiva de rasgos situacionales y discursivos de los dos cibergéneros 


\section{METODOLOGÍA. CORPUS, OBJETO DE ANÁLISIS, VARIABLES E HIPÓ- TESIS}

El objeto de estudio de esta investigación es determinar cómo actúa discursivamente el internauta ante su desacuerdo respecto a lo dicho previamente por otro emisor, es decir, el sujeto manifiesta su opinión contraria o disconformidad en relación a lo dicho en el post o noticia inicial y, sobre todo, a lo expresado por otro internauta en una intervención anterior.

El desacuerdo puede implicar un empleo gradual de las estrategias de (des)cortesía: de la cortesía a la descortesía y viceversa, tal y como se detalla en el esquema (6). En general, la cortesía comunicativa puede manifestarse porque se atenúa lo dicho para rebajar el desacuerdo, en lo que Albelda y Barros (2013: 21) denominan cortesía mitigadora: "es aquella cortesía que convive con un posible riesgo de amenazas y su finalidad es evitarlas o repararlas. (...) La atenuación es uno de los recursos más comunes en la cortesía mitigadora.”; en cambio, la descortesía suele vincularse a procedimientos de intensificación al descalificar la imagen del que opina de un modo acentuado, tal y como establecen Albelda y Barros (2013: 23): "La descortesía supone la realización de una agresión o amenaza a la imagen de nuestros interlocutores, en principio, de manera intencionada y deliberada. [...] En cualquier caso, la descortesía comunicativa actúa como desestabilizadora de la relación interpersonal entre los hablantes". Estas autoras sostienen que en la identificación de la descortesía cabe tener presente la intención del hablante y la interpretación del oyente.

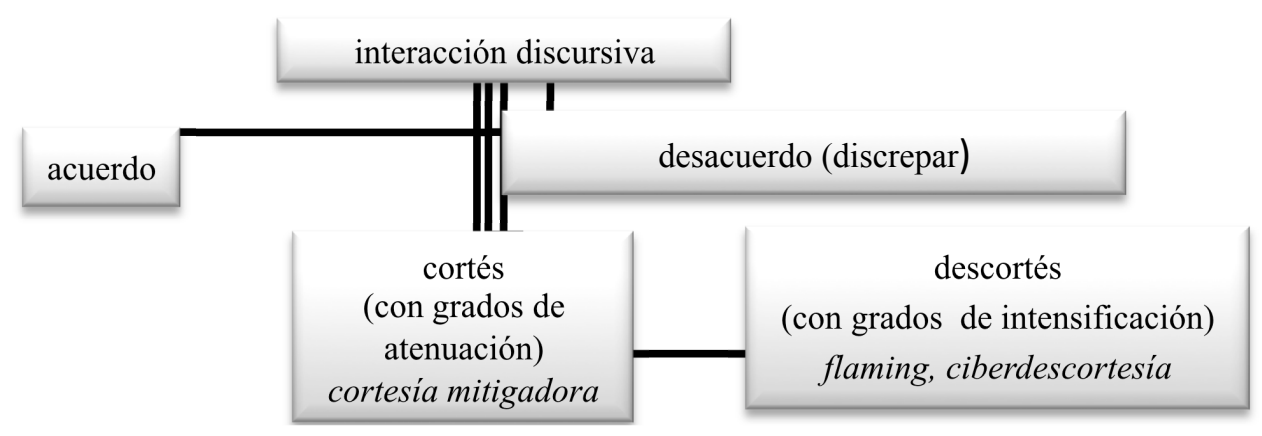

(6) Representación de las formas de interacción discursiva de los internautas

De este modo, se trataría de comprobar si existe cortesía mitigadora o los grados de intensificación de lo descortés o ciberdescortesía en las dos interacciones polifónicas digitales. Todo ello desde una perspectiva pragmática variacionista, cultural y contextual (Bravo 2005) y teniendo en cuenta las aportaciones de Hernández Flores (2013) sobre la tipología de las actividades de imagen en la interacción comunicativa. En los dos géneros soporte implicados se constata un grado de distancia y formalidad distinta: en el Facebook de ViajaconTuMascota.com el post inicial es más informal y en el periódico digital 20minutos.es la noticia es más formal. Esto haría esperar que en los comentarios reactivos a la información periodística se encontrase mayor cortesía entre los emisores y quizá una atenuación 
respecto a lo dicho como estrategia para expresar una opinión. Sin embargo, la observación inicial de las muestras de habla conduce a la idea contraria: las intervenciones reactivas en ViajaconTuMascota.com son más atenuadas y corteses en contraste con los comentarios de los lectores, más descorteses e intensificados.

Esto obedecería, como hipótesis de partida, a que los usuarios de ViajaconTuMascota. com pertenecen a una comunidad virtual y, en general, responden de lo dicho con su identidad real, frente a la falta de adscripción de los lectores de 20minutos.es a un grupo de referencia y la ocultación de su identidad al emplear un apodo.

Para comprobar esta hipótesis, se han recopilado noticias sobre mascotas para que pudieran suscitar un similar grado de polémica y girasen en torno a una temática parecida a la del Facebook analizado. Así, por ejemplo, las noticias en torno a una temática como la turismofobia, en principio, parecían implicar un grado mucho mayor de desencuentro, con afirmaciones del tipo: «lo dicho, tu no eres mas tonto, porque es imposible.» https:/www.20minutos.es/ noticia/3111276/0/turismofobia-en-espana-claves/. Aunque como apunta Noblía (2015: 17) en relación con los medios informativos digitales: "Así los ingredientes de una receta o el color de un par de zapatos desencadena la agresión del mismo modo que las diferentes posiciones sobre la guerra de Malvinas o la pesificación de la economía en la Argentina".

En concreto, se han revisado diferentes posts con sus comentarios, y se han seleccionado cinco posts y cinco noticias vinculadas con el ámbito de las mascotas, tal y como se muestra en la tabla (7). De esta revisión, se han descrito aquellas intervenciones de los seguidores/ lectores que suponían un desacuerdo bien con el post o noticia inicial, bien con lo afirmado por otros seguidores/lectores.

Téngase en cuenta que las intervenciones reactivas pueden ser a un post o noticia inicial o a comentarios de seguidores o lectores, que a su vez van ocasionando nuevas intervenciones reactivas en una escisión polifónica. En cualquier caso, el análisis no plantea una cuantificación de los datos, que siempre debería ser proporcional a las distintas muestras obtenidas. Se trata de un estudio exploratorio y cualitativo para describir las muestras de habla y determinar las posibles variables del usuario y del evento comunicativo concreto ${ }^{3}$, descritas en el apartado anterior: + /-pertenencia a una comunidad virtual $\mathrm{y}+/$ - identidad real.

En los ejemplos se han sustituido los posibles nombres reales. Todos los ejemplos se han emitido de mayo a septiembre de 2018. No se modifica el texto a pesar de los errores ortográficos. Tampoco se incorpora el enlace concreto para favorecer el anonimato.

\begin{tabular}{|l|l|}
\hline ViajaconTuMascota.com (Facebook) & 20minutos.es (periódico) \\
\hline $\begin{array}{l}{[1] \text { Complementos para perros }} \\
(235 \text { comentarios) }\end{array}$ & {$[1]_{i}$ Cuáles son las razas de perro más y menos } \\
$\begin{array}{l}\text { inteligentes? } \text { (24 comentarios) } \\
\text { las personas }(93 \text { comentarios })\end{array}$ & {$[2]_{\text {¿Cómo afecta la ola de calor a los perros y }}$ gatos? (13 comentarios) } \\
\hline
\end{tabular}

3 Las variables dependerán de las características del género analizado (Fuentes y Alcaide, 2008; Fuentes 2013; Blas Arroyo 2014).

4 Se revisan los 100 primeros más relevantes. Es en la propia página donde se califican como relevantes las intervenciones de amigos y las que más réplicas generan. 


\begin{tabular}{|c|c|}
\hline ViajaconTuMascota.com (Facebook) & 20minutos.es (periódico) \\
\hline $\begin{array}{l}\text { [3] Hay quien desconoce que en CERCANÍAS } \\
\text { de RENFE puedes viajar con perro } \\
\text { ( } 74 \text { comentarios) }\end{array}$ & $\begin{array}{l}{[3]_{\text {¿Perros con correa o sueltos? Horarios, }} \text { lugares y obligaciones de los dueños en Madrid }} \\
\text { (31 comentarios) }\end{array}$ \\
\hline $\begin{array}{l}\text { [4] Buenos días! Encontrarte esto en la entrada } \\
\text { de Media Markt es viuw viuw viui } \\
\text { (58 comentarios) }\end{array}$ & $\begin{array}{l}\text { [4] La Policía alerta de la proliferación de } \\
\text { salchichas con clavos para matar perros } \\
\text { (265 comentarios) }\end{array}$ \\
\hline $\begin{array}{l}\text { [5] Esta semana he volado por primera } \\
\text { vez en mis dos años y cuatro meses de vida. } \\
\text { ( } 66 \text { comentarios) }\end{array}$ & $\begin{array}{l}\text { [5] Muere un perro asfixiado de calor en el } \\
\text { interior de un coche en Fuenlabrada } \\
\text { ( } 62 \text { comentarios) }\end{array}$ \\
\hline
\end{tabular}

(7) Tabla con los datos de los cibergéneros analizados: títulos y número de comentarios

\section{ANÁLISIS DE LOS DATOS}

Organizamos el análisis del corpus a partir de la caracterización de tres tipos de elementos:

1) indicicios de desacuerdo: la extensión de las escisiones y ciertos elementos discursivos (mira, pero, un saludo).

2) indicadores de descortesía: los insultos y los disfemismos.

3) indicadores de cortesía mitigadora: las risas y la subjetivización, como atenuadores de los desacuerdos.

\subsection{Indicios de desacuerdo}

\subsubsection{La extensión de las escisiones polifónicas}

Aquello que inicialmente se ha planteado en este estudio como un desacuerdo respecto a lo dicho anteriormente, en el caso de los comentarios digitales se ha transformado en una clara hostilidad y agresividad verbal y en lo que se conoce en la actualidad con el término inglés flaming, que en tantos estudios se ha incorporado.

En los dos casos analizados, el desacuerdo suele plasmarse visualmente con una especie de escisión dialógica o polifónica ${ }^{5}$, ya que cuando surge mayor desacuerdo y enfrentamiento verbal no es exactamente con el post o noticia inicial (que no se implica ni participa activamente en estos conflictos), sino entre los diferentes participantes de esta interacción discursiva.

En el caso de ViajaconTuMascota, las escisiones se muestran como respuestas no desplegadas a una intervención iniciativa anterior, y a veces con el nombre(s) de ese emisor(es) en la intervención reactiva, ya que no indica gráficamente a quién se responde. A mayor número de respuestas, es posible un mayor grado de desacuerdo. Cuando se despliegan las

5 Así, Fuentes y Alcaide (2008: 23-25) indican estrategias descorteses en los medios (televisión) consistentes en la gestión del turno. 
respuestas quedan sangradas de un modo uniforme a la derecha (seguidor 2, 3, 4, 5), aunque entre ellas se produzcan a su vez nuevas escisiones, esto es, a pesar de que el seguidor 4 haya podido responder al seguidor 2 y 3 , tal y como se representa en el esquema (8):

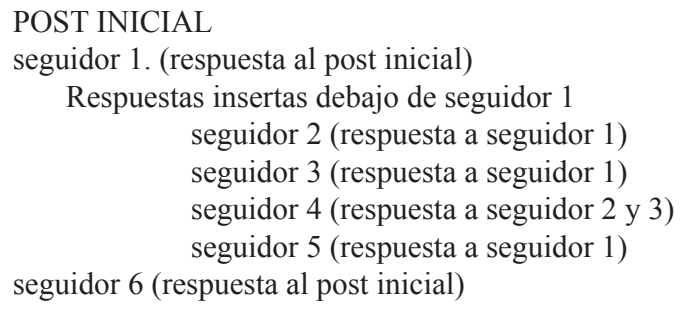

(8) Representación visual de las escisiones del Facebook

En cambio, en 20minutos.es las escisiones se muestran sucesivamente sangradas hacia la derecha, tal y como se plasma en el esquema (9). Normalmente, en los temas seleccionados los comentarios son cuantitativamente menos frecuentes que en ViajaconTuMascota, excepto en un caso. Parece que a mayor número de comentarios, más probabilidad de desacuerdo y conflicto.

\section{NOTICIA INICIAL}

lector 1. (comentario a la noticia inicial)

Comentarios insertos debajo de lector 1 lector 2 (comentario a lector 1$)$ lector 3 (comentario a lector 2) lector 4 (comentario a lector 3$)$ lector 5 (comentario a lector 4)

lector 6 (comentario a la noticia inicial)

(9) Representación visual de las escisiones de 20.minutos.es

En algunas de estas escisiones se produce un alejamiento del tema principal del post o noticia. De hecho, en 20.minutos.es surge una polémica discursiva con un elevado grado de descortesía y agresividad verbal entre dos tipos de lectores: a favor y en contra de las mascotas (ocasionan molestias, defecan en la calle, constituyen un peligro, etc.), con independencia de la noticia y temática específica sobre perros, esto es: se suele constatar un alejamiento del tema de la noticia aunque el debate siga versando sobre animales. En este sentido, Noblía (2015: 26) ya había indicado: "los comentarios se encuentran vinculados con una noticia particular y, si bien se encuadran en ella, muchas veces no se vinculan con su contenido." Es más, algunos internautas aprovechan para lanzar sus agresiones a sujetos que nada tienen que ver con este tema, como sucede en (10): 
(10)

-Naranja6 Hasta los güevos de los perritos, de las feministas, de Cataluña, de los animalistas y de toda las demás mierda que parece ser cosa principal en esta mierda de vida... Mierda de vida para los periodistas, quiero decir.

Y, en el caso de ViajaconTuMascota, se aprecia un menor alejamiento de la temática principal. Véase, como muestra, un debate en relación con la ortografía ${ }^{6}$, tal y como se reproduce en (11), al escribir una participante micro(h)ondas con hache. La cuestión ortográfica se aleja del tema del post y da lugar a una escisión conversacional:

(11)

-Alejandro: Nerea por favor, corrige lo de “ microhondas” con 'h' hace mucho daño a la vista

-Patricia: Pos me encanta la foto y me gusta la aclaración en el anuncio... [...]

-Joan: No hay que hacer publicidad engañosa

-Nerea: Ay! ya salio el licenciado, eso es lo mejor ke puedes aportar lo de la h? For you: MICROHONDAS MICROHONDAS MICROHONDAS:)

[ViajaconTuMascota]

\subsubsection{Otros indicios discursivos de desacuerdo: mira, pero y un saludo}

Tanto el marcador del control del contacto mira como la conjunción adversativa pero pueden ser indicios de desacuerdo, tal y como sucede en (12): cuando mira aparece en estos textos escritos en posición inicial de intervención, y pero refleja una contraargumentación en mitad de intervención (sí...pero no...). Del mismo modo, el saludo final explícito, la marca epistolar de despedida, un saludo, aunque se pueda considerar como un atenuador del desacuerdo (Castro 2017), a nuestro juicio, sirve para establecer una distancia entre los interlocutores porque es una forma no habitual ni esperable en este tipo de mensajes ${ }^{7}$. Implica un refuerzo del alejamiento y de la distancia respecto al interlocutor, con el que se está en desacuerdo. En estos casos, la despedida explícita se aleja de las convenciones de los comentarios en internet y quizá es también una forma de cerrar la continuidad de las posibles respuestas, pero solo se da en el caso de Facebook:

\section{(12)}

-Marta: Mira desde el cariño y sin entrar en discusiones ninguna tengo dos perros y una es un Pincher de $2 \mathrm{~kg}$ hasta en verano la tengo q tapar cuando la echo en la canasta de la.pega todo el día tiritando y ahora en invierno en Sevilla no es que haga mucho frío pero si no fuera por ponerle un chaquetón o sudadera la perra ni saldría una cosa no quita la otra no la voy a vestir de dior jajaj del chino me vale pero lo pasa muy mal el animal y no lo trato como peluche ni como un bebé se diferenciar entre mi hijo y mis perros. Un saludo.- [ViajaconTuMascota]

6 En los dos géneros digitales el empleo de incorrecciones ortográficas por parte de un usuario y la corrección por parte de otro ocasiona por lo general un debate. Seguramente porque se daña la imagen personal del emisor.

7 Estas marcas epistolares de cierre quedan como posible análisis de un estudio posterior. 


\subsection{Indicadores de descortesía ${ }^{8}$ : el insulto y los disfemismos}

El insulto $^{9}$ se puede clasificar como el mayor grado de descortesía ya que se emite para ofender, molestar o despreciar. En nuestro caso se podrían diferenciar dos tipos de descortesía a partir del empleo de términos disfemísticos y/o insultos y si se daña la imagen o se impone una actuación. También se considera más directo si el ataque a la imagen o imposición va dirigida al receptor $(t u ́)$ y menos directo o indirecto si se impersonaliza o se incluye al nosotros en el eje deíctico, como se muestra en el esquema de (13):

1) ataque o daño a la imagen del interlocutor: en una posible escala de agresividad y ofensa (de más 1.1.1 a menos 1.2.2)

\section{1 directo apelativo (a un tú):}

1.1.1 con término disfemístico: eres un gilipollas

1.1.2 sin término disfemístico: eres un cretino

1.2 indirecto apelativo: (a lo dicho por el tú, al nosotros, etc.)

1.2.1 con término disfemístico: eso que dices es una gilipollez, el ecologismo nos la suda

1.2.2 sin término disfemístico: eso que propones es absurdo, eso no es inteligente

2) imposición en la actuación del interlocutor: en una posible escala de agresividad y ofensa (de más 2.1.1 a menos 2.2.2)

\section{1 directo:}

2.1.1 con término disfemístico: vete a cagar

2.1.2 sin término disfemístico: vete por donde pelan los pepinos

\section{2 indirecto:}

2.2.1 con término disfemístico: a quien no le guste, que se vaya a tomar por culo

2.2.2 sin término disfemístico: a quien no le guste, ya sabe

(13) Esquema de tipos de descortesía en relación a la imagen y actuación del interlocutor

En el caso de esta página de Facebook se emiten juicios de valor sobre la acción dicha o realizada por otro (es una gilipollez), pero no suelen efectuarse sobre las personas o una persona en concreto (Pues a mi me encanta la idea y pienso ir y al que no le guste que le den $x$ donde amargan los pepinos) o incluso se incluye al propio emisor en el grupo de referencia. El término malsonante gilipollez es el más frecuente, seguido de la calificación de estupidez.

Como ejemplo de 1.1.1, se puede incluir el apelativo directo al tú con término disfemístico, de (14), toca cullons, un catalanismo utilizado por la procedencia geográfica del hablante o como atenuación frente a (tocacojones):

-Federica: Nerea tú eres un toca cullons [ViajaconTuMascota]

8 En este caso, no consideramos que se pueda hablar de anticortesía (Zimmermann 2005: 264-265).

9 La bibliografía que trata de definir este concepto es muy amplia, abarca diferentes perspectivas y establece una tipología variada (Gómez Molina 2002; Colin 2005; González Sanz 2010; Blas Arroyo 2014). 
Como muestra de 1.2.1, apelación no dirigida directamente al tú con término disfemístico, se considerarían los siguientes ejemplos de (15):

(15)

-Yolanda: A mí me parece una soberana gilipollez. De talla XXL. Menos maltrato y abandono y más adorarlos como perros, no como si fueran Oriana de GH, coño. [ViajaconTuMascota]

-Jose: Soberana gilipollez; son perros, no juguetes ni muñequitas. Y promocionar estas payasadas comerciales, en fin. [ViajaconTuMascota.]

-Ester: Hay cuanta sstupidez, agggg, puta humanidad. [ViajaconTuMascota]

-Natalia: Vaya Frase mas estupida: si no va a mi lado no viajo haha. [ViajaconTuMascota]

-Nerea: Menuda estupidez de comentario en serio... yo no, pero hay gente que se cree cualquier cosa, como recargar un movil en el microhondas y bobadas varias.

-Marián: El mundo no es responsable de las imbecilidades de algunos

[ViajaconTuMascota]

En menor escala, la inclusión de un nosotros como sujeto atenúa la descortesía al integrarse el hablante en el grupo objeto de crítica (el consumo responsable nos la suda) o más indirectamente (para que caigamos comprando, eso es una mierda capitalista). En ambos casos, algunos interlocutores anteriores habían mostrado su intención y entusiasmo en comprar ropa para perros; de ahí la crítica indirecta: al comprar esa ropa no eres responsable en relación con el ecologismo y eres un consumista de (16).

\section{(16)}

-Teresa: Vamos que el único motivo por el que es dog friendly es porque puedes comprar ropa que no necesita tu pero. Amamos a los animales pero lo del ecologismo y el consumo responsable nos la suda [ViajaconTuMascota]

- Laura: Me parece que a quien le guste de lujo. Para mi el ver perros abandonados y perreras repletas, refugios y protectoras sin ayudas y otros fomentando el consumismo hasta en los perros para que caigamos comprando, eso es una mierda capitalista. [Viajacon TuMascota]

Una muestra de crítica indirecta sin término disfemístico se encontraría en (17), en el que se impersonaliza el objeto de crítica (nadie será tan cruel de ir a juego con su perro, si se quiere jugar...), aunque se infiere por el cotexto previo que se refiere a los interlocutores que han mostrado su deseo de comprar ropa al perro:

\section{(17)}

-Pepa: Madre mía espero q nadie sea tan cruel d querer ir a juego con su perro, los perros son perros, no se les viste, no se les echa colonia, no van en carritos como bebés..... Madre mía si se quiere jugar a las mamás q se compren un reborn pero a los perros dejarlos ser perros. [ViajaconTuMascota] 
En 2.1.2, imposición a un posible receptor impersonalizado (al que no le guste) sin término disfemístico explícito, se podría englobar el ejemplo de (18), aunque la interdicción sería una cuestión gradual (que te den por posibilita diversas opciones fraseológicas):

(18)

- Blanca: Pues a mi me encanta la idea y pienso ir y al que no le guste que le den $\mathbf{x}$ donde amargan los pepinos [ViajaconTuMascota]

En síntesis, en el Facebook de ViajaconTuMascota predomina el daño a la imagen del interlocutor a través de una calificación despectiva a lo dicho por el tú (eso es una gilipollez) frente al insulto al propio tú (eres un gilipollas).

En cambio, en los comentarios de 20minutos.es resultan habituales los insultos explícitos dirigidos a un tú, incluso con intensificación de mayúscula (ERES UNA MALA PERSONA, Ojalá no olieran tu putrefacto olor a.... m i e r $d$ a, si, ese que desprendes) y el empleo de numerosos términos interdictos (hijos de p...), a veces solo sugeridos por las iniciales a las que siguen puntos suspensivos en (19):

(19)

-El Verrugas: Tener un pu...o perro es una esclavitud: hay que gastarse una pasta en el usurero del veterinario estafador, en comida, hay que sacarlo varias veces al día a mear y cagar (yo si meo en la calle soy multado; estos hijos de p... de los perros no) y todo por que te saque la lengua y te diga Arrrggg envuelto de babas y mal aliento. Y cuandro ladran es para matarlos sobre todo si te despiertan un sábado a las 7 de la mañana

-gotarca: Por la formade hablar, tú si que eres el candidato ideal para sacar a pasear por la calle, bien atadito y con bozal, no vaya a ser que muerdas a alguien. $Y$ de paso, tampoco te iría mal ir vacunado de la rabia.

-Madrox: claro, los veterinarios tienen que vivir del aire [20minutos.es]

-El Verrugas: El mas inteligente es el perro pachón. Pero bueno: el mejor perro es el perro muerto.

-madericas: ¡iEN EL ALMA DEBES TENER LAS VERRUGAS!!!!! ERES UNA MALA PERSONA

-AKIRA RETURNS

El peor bicho del mundo es el ser humano, CAMPEÓN !!!!!!!!!!

-AKIRA RETURNS: Espero que nunca, nunca, te salve un perro de los que rescatan gente de entre los restos de una catástrofe. Nunca jamás....... Ojalá no olieran tu putrefacto olor a.... m i e $\mathbf{r} \mathbf{d}$ a, si, ese que desprendes....... [20minutos.es]

También surgen los insultos hacia un grupo heterogéneo en (20), no explícitamente vinculado al comentarista anterior ni siquiera relacionado:

(20)

-Naranja6_ Hasta los güevos de los perritos, de las feministas, de Cataluña, de los animalistas y de toda las demás mierda que parece ser cosa principal en esta mierda de vida... Mierda de vida para los periodistas, quiero decir. [20minutos]

-truji: Asco de perros, mas bien de mascotas-jugetes animados perrunos en manos de gente caprichosa jodiendo al vecino [20minutos] 
Se muestran del mismo modo una especie de actos amenazantes en (21):

(21)

-horatio: Entonces cuando tengo diarrea voy a defecar en tu puerta y así lo recoge tu madre o te lo llevas tú en los zapatos!!!! [20minutos]

Así pues, en los comentarios de 20.minutos.es predominaría lo que Fuentes (2009a) consideraría como función argumentativa (agredir y enfadar al tú con un insulto) e incluso como función social (presentar una imagen agresiva del propio hablante.) En cambio, en el ViajaconTuMascota nunca se pretende presentar esta imagen agresiva del propio hablante ni enfadar. En todo caso y como Fuentes (2009a) también apunta para las redes sociales, en esta última página la estrategia de la descortesía ${ }^{10}$ solo se emplea argumentativamente para imponer una opinión sobre el otro al descalificar su opinión. En la misma línea, Castro (2017: 41-42) considera que el hablante no pretende la ruptura de las relaciones; al contrario, intenta generar controversia y provocar al otro y, además, añade que se configura como una especie de estilo agresivo ${ }^{11}$ cuya recursividad contribuye a que pierda su capacidad de ofensa y contribuye al espectáculo (Díaz Pérez 2012, Mancera 2015).

\subsection{Indicadores de cortesía mitigadora}

Aunque no se está de acuerdo, los seguidores del Facebook suelen emplear cortesía mitigadora (Albelda y Barros 2013), es decir, recursos para mitigar el daño a la imagen del otro.

\subsubsection{El humor, las risas, los emojis y el perdón}

En los comentarios del Facebook descrito aparecen los recursos propios de un habla de proximidad: las risas (jaja), las imágenes en movimiento, los emojis, la búsqueda de un mensaje ingenioso, lúdico y humorístico, los me gusta y el estoy de acuerdo, tal y como se observa en los ejemplos posteriores de (22), y los rasgos lingüísticos de sus textos se aproximan al escribo como hablo, a las características de un registro coloquial de proximidad y a los aspectos específicos de los textos digitales. Todo esto no se registra en los comentarios de las noticias y se consideraría como atenuante del desacuerdo en el marco de la cortesía mitigadora.

\section{(22)}

-Celia: Laura bueno, eso pasa también con los humanos. Mientras tú tienes Facebook e internet, muchos no tienen ni dónde caerse muertos

-Laura Celia jeje, como tú - . A eso me refiero, a los contrastes tan grandes que hay por el sistema consumista que tenemos. Saludos

-Alicia: Un perro es un perro y un vaso es un vaso 30 . No es comparable. Por mucho que amemos a nuestros peludos, nos aportan cosas distintas a las personas, lo.mismo que la música y un libro. [ViajaconTuMascota]

10 En el análisis cuantitativo de Mancera (2009) sobre cinco diarios digitales, incluido 20Minutos.es, concluye que los actos de amenaza de la imagen son mucho más abundantes que los de cortesía valorizante.

11 Díaz Pérez (2012) analiza diferentes tipos de recursos para mostrar esta agresividad: desde aspectos formalestipográficos, mecanismos morfológicos, léxicos y semánticos hasta el tipo de actos de habla y sus enunciados. 
-Bendita Lokura Viajacontumascota.com...... A la hoguera iiiiiii Jajajajsjajaj....... Que va sin cadena y sin bozal para una foto en un vagón VACIO iiiiii.....Y ahora lo ven en el Congreso y no podremos viajar en tren NUNCA MAS DE LOS JAMASES iiiiii Jajajajsjajaj iiii [ViajaconTuMascota]

En (23) se contraargumenta con humor (de talla XXL, te compras una escoba):

(23)

- Yolanda: A mí me parece una soberana gilipollez. De talla XXL. Menos maltrato y abandono y más adorarlos como perros, no como si fueran Oriana de GH, coño.

[ViajaconTuMascota]

-Luis: Pepe si no te gustan los perros te compras un gato o si no una escoba y te vas de viaje con ella como las brujas [ViajaconTuMascota]

Es más, los seguidores también aluden de un modo explícito a la necesidad de respeto al otro y se utilizan elementos como perdón o perdonar, como sucede en (24):

María: Te doy la razón, pero puntualizar que mi perro de 7kl no es un tocacojones, es un cielo el cual viene conmigo a todos los lados y lo adoran. No hace falta hablar mal de otros para tener toda la razón del mundo.

-Sonia: María por eso puse por norma general. [ViajaconTuMascota]

-Saratruski Atruski Suski Perdonar porque no he especificado que no generalizo que todos los perros pequeños sean así. Eso ha sido error mio. Yo lo que quería exponer es que si el perro pasa de unos ciertos kilos en muchísimos sitios nos cortan mucho cosa que no pasa con los perros pequeños y eso es una realidad. [Viajacon TuMascota]

Si bien es cierto que también puede emplearse perdonar con intención desafiante o recriminatoria como sucede en la intervención de (25), en la que va seguido de tres signos de interrogación:

Irene: Sonia perdona??? Nosotros por motivos que no vienen al caso nos tuvimos que ir a vivir a USA. mi perro tenía 10 años y por supuesto que viajó con nosotros.... según tú somos unos irresponsables por llevarnos al perro.... entonces, ¿Qué teníamos qué haber hecho... abandonarlo??? [ViajaconTuMascota]

En algunos de los comentarios de noticias de (26), se constata el intento de humor y de ser ingenioso, e incluso se reproducen algunas risas, pero siempre en un marco de clara hostilidad:

(26)

-Cinefilo2.0

$\mathrm{Y}$ aqui preoucpados por los perritos. Tócate el ciruelo

-VK Valledelkas

ven.. que te toque el ciruelo 
-Wolfito Si tengo una (que cogi de la calle y ha hecho un bien impagado en la familia: por ejemplo con un familiar anciano enfermo mental que le transmitia tranquilidad, obviamente tratado tambien con pastillas) Que mal te hago yo a ti si me quiero informar? -tripero

Ellos valen mas que muchos, incluyendote a ti hombre ciruelo [20minutos]

-ordel: oNbatir...COJONANTE

-Malaspulgas Barcelona: Y NO RAPARLOS!!!!!! el pelo limpio,desenredado y sin muda.....se le puede cortar y arreglar,pero siempre manteniendo un largo que no deje expuesta su piel y pueda termoregular y disipar la radiacion solar y el calor que incide sobre ellos

-Polecat pula nga: A un gato calvo también jajajaja hay razas sin pelo. Joer como tratarias a cualquiera de la familia menos a la suegra jaja, no sea que la dejes en la gasolinera [20minutos.es]

En suma, los emoticonos, las risas, los recursos humorísticos o la solicitud de perdón se vinculan en ViajaconTuMascota.com a estrategias para atenuar los desacuerdos en el marco de una cortesía mitigadora; en cambio, el humor soez y con disfemismos impera en los comentarios de 20.Minutos.es, por lo que se mantiene la hostilidad y no se puede enmarcar en una cortesía mitigadora.

\subsubsection{Las personas de la enunciación: a mí me parece}

En el Facebook analizado también se registran elementos de atenuación ${ }^{12}$ en (27) desde la subjetivización del yo: es me parece muy mal, no lo veo mal, es verdad que; y se da parcialmente la razón y solo después se contraargumenta con pero:

-Sonia: Carla eso de que por norma general todos los pequeños sean toca cojones te lo sacas de la manga. Yo tengo 5 perros pequeños y ninguno es toca cojones, todos son educados. Me parece muy mal que no te dejaran entrar con tu perro de $40 \mathrm{~kg}$ ya que todos deberían tener derecho pero también me parece mal que para quejarte de esa situación tengas que chafar al resto de perros por su peso. Si pides tolerancia, demuestra que tú también lo eres. Los perros bien educados pueden pesar $1 \mathrm{~kg}$ o $60 \mathrm{~kg}$, depende del dueño. Un saludo -Rosa: Eso iba a decir yo..Que tendra que ver la educación del perro con el peso??:-(:) [ViajaconTuMascota]

-Sonia: Yo no soy partidaria de disfrazar a los, perros, pero almenos mi Yuk es super friolero, si tienen cosas interesante de abrigo, no lo veo mal. [ViajaconTuMascota]

-Elena: Los perros son perros. Es verdad que en invierno, a determinadas razas, en determinados ambientes, no les viene mal ponerles algo (aunque ellos están preparados para adaptarse sin necesidad de ropa), peroesto me parece... son ANIMALES. Y que

12 Rasgos similares son citados por Ferrer y Sánchez (2005) en el desacuerdo conversacional: reformulación de argumentos, sentimiento seguido de contraargumentación (sí, pero...), modalizadores (a mí me aparece) e interrogaciones modalizadoras (¿no?). Todo ello se constituye como atenuadores y estrategias de cortesía para favorecer una comunicación más dialogante ante un disenso. 
cada uno haga lo que quiera, pero lo de comprarle un modelito a juego...luchemos porque nos dejen ir con ellos a más lugares, que se endurezcan las penas contra el abandono y maltrato animal, que bajen los previos de las vacunas y consultas veterinarias, que se facilite en las viviendas de alquiler poder tener una mascota... eso si ayuda a los animales [ViajaconTuMascota]

En definitiva, el seguidor de ViajaconTuMascota.com recurre a estrategias de subjetividad para atenuar lo dicho y afirmado ( $A$ mí me parece); en cambio, en 20.Minutos.es no se suelen registrar estos usos atenuadores para manifestar la opinión.

\section{CONCLUSIONES}

En el siglo XXI y en la era digital, sorprenden las numerosas intervenciones que no aportan información y solo registran opiniones o comentarios de los usuarios. Surge la actividad de la escritura como una forma activa de participación, pero, a nuestro juicio, sin tenor transaccional informativo explícito. Es el opinar por opinar, comentar por comentar, agredir por agredir desde la subjetividad del yo, y lejos de la pretendida democracia electrónica que favorece la interacción comunicativa de los ciudadanos en los acontecimientos de la vida cotidiana (Díaz Pérez 2012). Es, curiosamente, una interacción promovida por entidades privadas, en este caso, la página comercial o el periódico digital para incorporar la participación del usuario como un valor añadido a la empresa: en la web 2.0 lo importante es generar opinión.

Los dos cibergéneros estudiados difieren notablemente en la expresión y en las muestras del desacuerdo: en la comunidad virtual de la página de Facebook la vinculación afectiva, el compartir algunas normas y valores y el mantenimiento de cierta identidad real favorecen que se suela mostrar acuerdo en un elevado número de intervenciones respecto al post inicial (en cierto modo informal) y que se mitigue el desacuerdo con el empleo de un lenguaje de proximidad, con emojis o desde la subjetividad del yo.

Por el contrario, en los comentarios de las noticias periodísticas (con un registro formal), el anonimato, la ocultación de la verdadera identidad, y la falta de adscripción de una comunidad virtual lleva al sujeto a la agresión verbal, al flaming, a la ciberdescortesía en los continuos desacuerdos. Resulta llamativo cómo el anonimato favorece que los sujetos escriban textos digitales con un elevado grado de agresividad. Se participa con esa identidad virtual que posibilita la ruptura de la cortesía comunicativa con una marcada agresividad verbal. Al amparo del apodo anónimo el sujeto lanza sus palabras como arma arrojadiza para ofender al otro. Además, esa ofensa, ese acto de agresión, es leído por el resto de internautas, a modo de audiencia: los ataques se convierten en objeto de espectáculo. Es más, los ataques forman parte ya de una especie de estilo agresivo habitual de este género.

No obstante, consideramos que en el caso de la interacción en la red social Facebook se deberían tener en cuenta los rasgos situacionales de cada página. Esto explicaría que la afirmación de Castro (2017: 45-46) en relación con las diferencias entre blogs y Facebook se pudiera aplicar también a nuestro discurso. En opinión de Castro (2017), los comentarios descorteses son más frecuentes en Facebook y Twitter porque los usuarios acceden a temas e información diversos que pueden estar en oposición a sus creencias e ideologías, y en los blogs se accede al compartir una afinidad. Esta explicación es la misma que incorporamos a nuestras conclu- 
siones: en el Facebook analizado existe una afinidad de vivencias que no se produce en los comentarios digitales periodísticos al seleccionar una temática general (los canes).

Nuestro estudio ha establecido una clasificación específica para estas intervenciones digitales de los indicios de desacuerdo o elementos discursivos que pueden ser indicadores de desacuerdo; de los indicadores de descortesía: elementos que manifiestan la descortesía; y unos indicadores de cortesía mitigadora. Y en especial, se defiende la necesaria interpretación contextual, ya que incluso una fórmula de despedida como saludos puede interpretarse de diferentes modos en función del contexto. Así, en los comentarios del Facebook destaca cómo la mera despedida explícita se convierte en marca de desacuerdo (atenuadora o no).

Será necesario ampliar el corpus textual con la compilación de más muestras de habla, con la inclusión de otros parámetros de los usuarios (edad, sexo, nacionalidad o ideología) y de los propios discursos (la ideología y la temática seleccionada del diario digital, el grupo/ comunidad de Facebook, el objeto de la descortesía y de la agresividad, otros tipos de discursos digitales) para obtener una perspectiva más amplia de los condicionantes, indicadores y parámetros de la (ciberdes)cortesía.

\section{REFERENCIAS BIBLIOGRÁFICAS}

Albelda, M.y Barros, M. J. (2013) La cortesía en la comunicación. Madrid: Arco Libros.

Arancibia, M. C. y Montecino, L. A. (2013) "El blog de comentarios a textos de opinión en ciberperiódicos: un género en constante reconstrucción”, Literatura y Lingüística, 28, pp. 1-13.

Blas Arroyo, J.L. (2001) “"No diga chorradas...': La descortesía en el debate político cara a cara. Una aproximación pragma-variacionista", Oralia, 4, pp. 9-46.

Blas Arroyo, J.L. (2014). "Factores condicionantes en la producción y recepción de la descortesía en un reality show. Una aproximación variacionista", Revista de Filología de La Universidad de La Laguna, 32, 17-43.

Bou, P. y Garcés-Conejos, P. (2014) "Conflict management in massive polylogues: A case study from YouTube", Journal of Pragmatics 73, pp. 19-36.

Bravo, D. (2005): "Categorías, tipologías y aplicaciones. Hacia una redefinición de la cortesía comunicativa", en Bravo, D. (ed.), pp. 21-52.

Bravo, D. (ed.) (2005) Estudios de la (des)cortesía en español. Categorías conceptuales y aplicaciones a corpora orales y escritos. Buenos Aires: Dunken.

Brenes, E. (2009) La agresividad verbal y sus mecanismos de expresión en el español actual. Tesis doctoral, Sevilla: Universidad de Sevilla: https://idus.us.es/xmlui/handle/11441/15333 (01-022018)

Brenes, E. y González Sanz, M. (2013): "La descortesía verbal en el medio televisivo. Análisis comparativo de tertulias políticas y de crónica social”, en Fuentes, C. (coord.), pp. 67-88.

Briz, A. (2012) "La constelación comunicativa coloquial: hacia un modo más dinámico de entender lo coloquial", Español actual: Revista de español vivo, 98, pp. 217-226

Briz, A. (2014) "Hablar electrónicamente por escrito", CHIMERA: Romance Corpora and Linguistic Studies, 1, pp. 77-89.

Castro, M. (2017) "Ataque a la imagen y descortesía en los comentarios de blogs en español peninsular", Philologia Hispalensis 31/1, pp. 37-63

Chierichietti, L. (2014) "Descortesía en las páginas de Facebook de festivales de música", Revista Normas, 4, pp. 27-48.

Colin, M. (2005) "Modelo interpretativo para el estudio del insulto", Estudios de Lingüistica Aplicada, 41, pp. 13-36. 
Crystal, D. (2002) El lenguaje e Internet. Madrid: Cambridge University Press.

Culpeper, J. et alii (2003) "Impoliteness revisited: with special reference to dynamic and prosodic aspects", Journal of Pragmatic, 35, pp. 145-157.

Díaz Pérez, J.C. (2012). Pragmalingüistica del disfemismo y la descortesía. Los actos de habla hostiles en los medios de comunicación virtual. Tesis doctoral. Madrid: Universidad Carlos III.

Ferrer, M.C.y Sánchez, C. (2005) "Multifuncionalidad de estrategias conversacionales en el discurso de la argumentación”, en Bravo, Diana (ed), pp. 145-162.

Fuentes, C. y Alcaide, E. (2008) (Des)cortesía, agresividad y violencia verbal en la sociedad actual. Sevilla: Universidad Internacional de Andalucía.

Fuentes, C. (2009a) "Cuando la descortesía se convierte en agresividad. Las listas de debate en el correo electrónico”, en Bravo, D. et al. (eds.). Aportes pragmáticos, sociopragmáticos y socioculturales a los estudios de la cortesía en español. Buenos Aires: Dunken, pp. 321-359.

Fuentes, C. (2009b) "Descortesía y agresividad bajo el anonimato: Internet", en Fuentes, Catalina y Alcaide, Esperanza (eds.). Manifestaciones textuales de la descortesía y agresividad verbal en diversos ámbitos comunicativos. Sevilla: Universidad Internacional de Andalucía, pp. 189-211.

Fuentes, C. (2013) "Los comentarios en la prensa digital", en Fuentes, C. (coord.). Imagen social y medios de comunicación. Madrid: Arco Libros, pp. 199-247.

Fuentes, C. (coord.) (2013) (Des)cortesía para el espectáculo: estudios de pragmática variacionista, Madrid, Arco Libro.

Gómez Molina, J.R. (2002) "El insulto en la interacción comunicativa. Estudio sociolingüístico", Oralia 5, pp. 103-132.

González, V. y Sanmartín, J. (2013) "Facebook y Discurso turístico: tenor funcional y estrategias pragmalingüísticas en turismo Madrid y Turismo Sevilla", en Cabedo, A. et al. (eds.). Estudios de Lingüistica: investigaciones, propuestas y aplicaciones. València: Universitat de València, pp. 243-253.

González Sanz, M. (2010) "Las funciones del insulto en debates políticos televisados", Discurso y Sociedad, 4, pp. 828- 852.

Hernández Flores, N. (2013) “Actividad de imagen: caracterización y tipología en la interacción comunicativa", Soprag 1(2), pp. 175-198

Kaul,.S. (2005) "Descortesía de fustigación por afiliación exacerbada o refractariedad", en Bravo, D. (ed.). pp., 299-318.

Kaul, S. y Cordisco, A. (2014). "La descortesía verbal en el contexto político-ideológico de las redes sociales", Revista de Filología, 32; pp. 145-162

Lea, M.; et al. (1992) "Flamming in computer-mediated communication: Observations, explanations and implications"; en Lea, M. (ed.) Contexts of Computer-Mediated Communication. London, Harvester-Wheatsheaf, pp. 89-112.

López, L. y González, C. (2013) "Las expresiones agresivas en los comentarios de los usuarios de los blogs periodísticos: un análisis por medio de la teoría de la valoración”, Tonos digital 24, pp. 1-12.

Mancera, A. (2009) "Manifestaciones de descortesía y violencia verbal en los foros de opinión digitales de los diarios españoles", Discurso \& Sociedad 3, 3, pp. 437-466: http://www.dissoc.org/ ediciones/v03n03/DS3(3)Mancera.pdf (01-02-2018)

Mancera, A. (2015) "Los estudios sobre (des)cortesía y actividades de imagen en las redes sociales: notas para un estado de la cuestión”, Textos en Proceso 1, pp. 50-70.

Mancera, A. y Pano, A. (2013) El español coloquial en las redes sociales. Madrid: Arco Libros.

Masip, P. (2011) "Comentarios de las noticias: la pesadilla de los cibermedios", Anuario ThinkEPI, 5, pp. 106-111: https://recyt.fecyt.es/index.php/ThinkEPI/article/viewFile/30478/16044 (01-022018) 
Moya, P. (2015) "Los comentarios de los usuarios en la prensa digital: una propuesta para su estudio desde el discurso mediado por ordenador y los estudios periodísticos", Caracteres. Estudios culturales y críticos de la esfera digital, 4, pp. 178-199.

Moya, P. y Carrió, M.L. (2018) "La atenuación en los comentarios sobre las noticias digitales en los periódicos de España y de Chile", Onomázein, 40, pp. 56-76.

Noblía, M.V. (2015) "Un pacto de mutua agresión: la negociación de la imagen y el rol de la audiencia en los diarios digitales. Los comentarios en el diario La Nación.com”, Textos en proceso, 1, pp. 16-49. DOI:10.17710/tep.2015.1.1.2nob.

Pardo, M.L. y Noblía, M.V. (2015) "Ni diálogo ni debate: la voz de la audiencia en los comentarios digitales sobre la pobreza", Revista Latinoamericana de Estudios del Discurso, 15, 2, pp. 117-137.

Parker, B. (2017) "Virtually Free Speech: The Problem of Unbridled Debates on Social Media", Intuition: The BYU Undergraduate Journal in Psychology, 12, pp. 107-119.

Ruiz, et al. (2010) "Conversación 2.0. y democracia. Análisis de los comentarios de los lectores y de la prensa digital catalana", Comunicación y sociedad, XXIII, 2, pp. 7-39.

Sal Paz, J. C. (2016) "El comentario digital como género periodístico. Análisis de la Gaceta de Tucumán", Aposta. Revista de Ciencias Sociales, 69, pp. 158-216.

Sanmartín, J. (2007) El chat. La conversación tecnológica. Madrid: Arco Libro.

Tabachnik, S. (2012) Lenguaje y juegos de escritura en la red: Una incursión por las comunidades virtuales. México: Universidad Autónoma Metropolitana.

Vivas, J. y Ridao, S. (2015) "Estrategias de (des)cortesía en redes sociales: análisis comparativo de facebook y twitter", Sintagma 27, pp. 73-87.

Vivas, J. (2014) "La cortesía valorizadora en las redes sociales. Análisis de un corpus de publicaciones en Facebook”, Pragmalingüistica, 22, pp. 154-172.

Vivas, J. (2015) “'Lo siento, pero me parecen horribles!!!', Análisis pragmalingüístico de la descortesía en la red social Facebook", Revista de Filología, 33; pp. 217-236

Yus, F. (2001) Ciberpragmática. El uso del lenguaje en Internet. Barcelona: Ariel Lingüística.

Zimmermann, K. (2005) “Construcción de la identidad y la anticortesía verbal”, en Bravo, D. (ed.). pp. 245-271. 